\title{
What is new in Open Access?
}

by ALMA SWAN

\section{INTRODUCTION}

A number of quite significant developments have taken place in Open Access over the last year or so. I have already documented some of the advances in Open Access publishing and in digital repositories (Swan, 2006). In this article the focus will be upon policy developments, technological developments, new aspects of researcher behaviour, and includes the laying of a few urban myths, on which topic we can begin.

\section{URBAN MYTHS ABOUT OPEN ACCESS}

\section{Urban myth 1: “ISI doesn't cover Open Access journals”}

ISI (Thomson Scientific) indexes around 200 Open Access journals (OAJs) for its Web of Science service. It applies the same criteria for inclusion in that index to Open Access journals as it does to subscription-based titles. In addition to these 'pure' Open Access journals, the Web of Science also indexes many other titles - so-called 'hybrid journals' - that offer authors the choice of paying a publication fee in return for their article being made Open Access. With almost all the major publishers now offering this option across a wide range of journals the amount of OA material indexed and monitored by Thomson is rising. Thomson has also moved to index the content of digital repositories (see later in this article).

\section{Urban myth 2: “Open Access journals are not good quality”}

The current popular measure of journal quality is the Journal Impact Factor, calculated by Thomson Scientific for its Journal Citation Index service. The calculation is based on a formula with a numerator of the number of citations to articles in a journal over a two-year period and a denominator of the number of articles published during that period.[1] Notwithstanding the fact that this is a very poor measure of the work of the individuals who publish in a journal, and that it is open to manipulation, the Journal Impact Factor remains the most-used and most-familiar metric for journal - and by proxy - research quality. By dint of being included in the Web of Science index, around 200 Open Access journals enjoy the prestige of having an official Impact Factor, thus denoting some measure of quality to these titles. Moreover, some OAJs enjoy particularly high impact factors: the most notable in this respect, PLoS Biology, romped straight to the top position in the General Biology category the first year it qualified for such a calculation (journals must have been published for at least two years before an impact factor can be calculated).

\section{Urban myth 3: "Paying a publication fee to Open Access journals corrupts peer review"}

This would be very significant and deeply damaging to the integrity of the scholarly communication system were it true. It is not. Open Access journals that charge an article-processing fee have a firewall between the peer review process and the charge-imposition system, ensuring that authors cannot pay to subvert the peer review procedure in a manner akin to vanity publishing. But the issue is interesting since it has largely been certain publishers who have been making this assertion: now that those publishers have themselves adopted a 'hybrid' Open Access offering we can presumably look forward to hearing no more about this.

\section{Urban myth 4: “Open Access journal business models are unsustainable”}

Well, they may yet prove to be, but time is passing and we are seeing a move towards Open Access publishing not away from it, suggesting that some publishers at least are finding ways to sustain their publications even while making their content free online. It is also of note that there are many different business models for OAJs over and above the article-processing fee model. A study by Kaufmann-Wills in 2005 showed that more than half of Open Access journals do not charge an article-processing fee at all (Kaufmann \& Wills, 2005). The study did not investigate in detail what the model is for those journals but some of the ways in which OAJs are supported without fees are by sponsorship, by advertising or by selling the hardcopy version. On that last point, Dr D.K. Sahu, founder and CEO of Medknow Publications in Mumbai (a publisher that now has 40 journals in medicine and related fields) has produced hard data on his own business model: he sells subscriptions to the printed journals but puts the articles 
online free of charge. Since he began doing this, article submissions have increased, citations to Medknow journal articles have increased and - unpredictably but happily for Medknow - subscriptions have increased (ref). Far from leading to unsustainability, Medknow's Open Access model has strengthened the trading base of the company.

Some publishers do charge an article-processing fee: two fully-commercial publishers that have a large number of OAJs and continue to launch new titles using this model are BioMed Central and Hindawi Publishing Corporation, with 160 and 52 journals respectively at the time of writing.

\section{PEER REVIEW}

A second development that has occurred in the last year or so is the beginning of experiments with new forms of peer review. That research output is peer reviewed in some way is of course critically important for upholding the quality of the scholarly record. It is also vital for the individual researcher, for their own credibility and for their claim to precedence with respect to a new advance in knowledge. Peer review should establish the validity of the work, whether it has been carried out appropriately, whether the correct interpretations of the results have been made and whether legitimate conclusions have been drawn. Traditionally, peer review has usually been carried out by sending submitted articles to two or more peers in the research community of the author and seeking their views on the work. In the age of print on paper this was really the only practicable way to handle the process. In the electronic age people are starting to realise that other methods may not only be possible but may be at least as appropriate and perhaps even preferable to established practice.

Two new kids on the block serve as examples of this. First, the journal Atmospheric Chemistry and Physics, published by Copernicus GmbH on behalf of the European Geosciences Union (EGU). operates a novel online twostage peer review process whereby papers are subjected to a rapid review and then published on the journal website. Here they are subjected to "interactive public discussion during which the referees' comments (anonymous or attributed), additional short comments by other members of the scientific community (attributed) and the authors' replies are also published”. Once this stage is complete, and if accepted, the final revised papers are published in the journal.

Second, the Public Library of Science, one of the best-known Open Access publishers, has just (December 2006) launched PLoS ONE. This service subjects articles in a wide range of scientific fields to an initial peer review process that ascertains only whether the work has methodological and practical rigour. Once this is established articles are posted onto the PLoS One website for open peer discussion.

There are other examples of formal peer review by new means and no doubt other journals and publishers will follow down this track. Indeed, it looks as though such experimentation will not rest with journals. A new development was also introduced in August 2005 at the particle physics Open Access repository, arXiv, which permits physicists to comment on articles deposited in the database: physicists blog their comments, link to the article in arXiv, 'ping' the arXiv site and arXiv provides a link to the blog next to the abstract of the article. This enables the sort of conversations physicists have been having in conferences or corridors over the decades to be carried out online, with a far larger group of discussants potentially able to participate than traditional discussion methods permit.

\section{INFORMAL OPENLY AVAILABLE MATERIAL}

I have included this section in somewhat speculative mode, which won't suit some readers but may interest others. It is about new ways of creating, collecting and disseminating scholarly material that is not formally peer-reviewed at all, and yet effectively becomes peer-reviewed by dint of being discussed and developed by a peer community working in collaborative mode. There isn't yet an agreed descriptor for this type of information or process, but everyone will be familiar with wikis and blogs and these are examples of the type of thing to which I am referring.

Of course, there are limitations to these informal channels, and they are especially unsuited - at least at the moment - to establishing claim on work or as a format of record, though such things may develop over time. Nonetheless, they are a significant means of disseminating findings or data in some areas already [2] and we may well see enormous developments in this arena as time goes on. 


\section{LOCATING OPEN ACCESS MATERIAL}

The amount of Open Access content appears to be growing, and new funder policies will enhance this still further (see later), but successfully locating Open Access articles has not always been simple. The free OAI search service, OAIster, was developed by the University of Michigan early on to provide a federated search facility across multiple, distributed repositories and other OA sources. Lately, though, some other players have moved onto the scene, including some big abstracting and indexing providers. Elsevier, for example, launched Scopus during 2004, a citation service that challenged head-on the Web of Science service from Thomson Scientific (ISI) in that it indexes the content of journals, including - of the 14,000 titles it indexes - over 500 Open Access journals. Scopus does not itself index Open Access repositories, but its sister service, Scirus, does, and Scirus links off the Scopus site thus bringing to the user in one place the means to search and retrieve the Open Access literature both in journals and in digital repositories.

Thomson Scientific has also launched into this area with its Web Citation Index. This is still in beta, and indexes only a relatively small number of repositories at the moment (though that number does include the physics arXiv, thus raising the number of articles indexed to well over half a million) but the plan is to continue to add repositories over time.

Scopus and the Web Citation Index are paid-for services, however, and thus available only to those whose libraries subscribe. The launch of Google Scholar late in 2005 changed things in this arena dramatically. Google Scholar, like its parent Google, is free to use and benefits, as a member of the Google product stable, from a high level of user acceptance and familiarity. Scholar does not do what Web of Science does - it does not systematically index according to a set of structured fields, for example - but it does use a Google algorithm that returns a highly relevant set of documents in response to a (usually amateur) user query. And that seems to be plenty good enough for most purposes of most scholars: around $60-70 \%$ of them use Google or Google Scholar as their first choice when searching for research articles.[3] Forget using Google Scholar for statistical analysis or more sophisticated searches using Boolean logic: it simply does not cater to this need. But most users want a quick answer to a simple query - the latest articles by a certain author, or from a certain research group, or on a certain topic - and Google Scholar does the business in this sense.

Not to be completely outdone, Microsoft launched Microsoft Live Academic Search in April 2006.

\section{POLICY DEVELOPMENTS}

The final issue that I wish to cover is that of the fast-moving developments with respect to policies on Open Access. Two years ago there were only a handful of formal policies, at the time from institutions in the vanguard of the movement who saw the future clearly.[4] Now, at the end of 2006, we have written policies from many more institutions and, importantly, funders.[5] The National Institutes of Health in the USA lead the way with an Open Access policy that was well-meaning but hopelessly ineffectual. Only around $4 \%$ of the NIH-funded research literature has been made Open Access as a result of this policy and it looks likely to be changed in the light of its failure to produce the intended results. Meanwhile other funders have seen much more clearly what needs to be done and have acted more effectively. The Wellcome Trust was the first funder to develop a mandatory policy on Open Access and this has now been followed by similar moves from six of the eight research councils in the UK. In the last couple of weeks similar developments in Australia on the part of the Australian Research Council and the National Health and Medical Research Council will ensure that the bulk of publicly funded Australian research output is Open Access in future. We can expect many more such initiatives in the next few years, at institutional, funder and government levels.

\section{NOTES}

1. The ISI impact factor. http://scientific.thomson.com/free/essays/journalcitationreports/impactfactor/

2. See, for example, the bioengineering community site: http://openwetware.org/wiki/Main_Page

3. Data obtained from a number of our own surveys of author behaviour.

4. See, for example, the University of Minho's policy at http://www.eprints.org/openaccess/policysignup/fullinfo.php?inst=Universidade\%20do\%20Minho 
5. ROARMAP (Registry of Open Access Repository Material Archiving Policies) as recommended by the Berlin Declaration: http://www.eprints.org/openaccess/policysignup/

\section{REFERENCES}

Kaufman, C. and A. Wills: The facts about Open Access. A study of the financial and non-financial effects of alternative business models for scholarly journals. Chichester, UK : ALPSP, October 2005. 134 p.

http://www.alpsp.org/ForceDownload.asp?id=70

Swan, A.: “Open Access: What has been going on?”. High Energy Physics Libraries Webzine, October 2006, issue 13. http://library.cern.ch/HEPLW/13/papers/1/

\section{WEB SITES REFERRED TO IN THE TEXT}

ArXiv.org. http://arxiv.org/

Atmospheric Chemistry and Physics. http://www.copernicus.org/EGU/acp/

Australian Research Council. http://www.arc.gov.au/

BioMed Central. http://www.biomedcentral.com/

Google Scholar. http://scholar.google.com/

Hindawi Publishing Corporation. http://www.hindawi.com/

Key Perspectives: http://www.keyperspectives.co.uk/

Live Academic Search. http://academic.live.com

Medknow Publications. http://www.medknow.com/

National Health and Medical Research Council. http://www.nhmrc.gov.au/

OAIster. http://oaister.umdl.umich.edu/o/oaister/

PLoS Biology. http://biology.plosjournals.org/perlserv/?request=index-html\&issn=1545-7885

PloS ONE. http://www.plosone.org/

Scirus. http://www.scirus.com/

Scopus. http://www.scopus.com/scopus/home.url

Web Citation Index. http://scientific.thomson.com/press/2005/8298416/

Wellcome Trust. http://www.wellcome.ac.uk/ 